\title{
Retinal vascular biomarkers for early detection and monitoring of Alzheimer's disease
}

\author{
S Frost ${ }^{1,2,3}$, Y Kanagasingam ${ }^{1,2}$, H Sohrabi $^{4}$, J Vignarajan ${ }^{1,2}$, P Bourgeat ${ }^{1,5}$, O Salvado ${ }^{1,5}$, V Villemagne ${ }^{5,6,7}$, CC Rowe $^{6}$, \\ S Lance Macaulay ${ }^{8}$, C Szoeke ${ }^{8,9}$, KA Ellis ${ }^{7,9,10}$, D Ames ${ }^{9,10}$, CL Masters ${ }^{7}$, S Rainey-Smith ${ }^{4}$, RN Martins ${ }^{4}$ and the AIBL Research \\ Group ${ }^{11}$
}

The earliest detectable change in Alzheimer's disease (AD) is the buildup of amyloid plaque in the brain. Early detection of $A D$, prior to irreversible neurological damage, is important for the efficacy of current interventions as well as for the development of new treatments. Although PiB-PET imaging and CSF amyloid are the gold standards for early AD diagnosis, there are practical limitations for population screening. AD-related pathology occurs primarily in the brain, but some of the hallmarks of the disease have also been shown to occur in other tissues, including the retina, which is more accessible for imaging. Retinal vascular changes and degeneration have previously been reported in $A D$ using optical coherence tomography and laser Doppler techniques. This report presents results from analysis of retinal photographs from $A D$ and healthy control participants from the Australian Imaging, Biomarkers and Lifestyle (AIBL) Flagship Study of Ageing. This is the first study to investigate retinal blood vessel changes with respect to amyloid plaque burden in the brain. We demonstrate relationships between retinal vascular parameters, neocortical brain amyloid plaque burden and AD. A number of RVPs were found to be different in AD. Two of these RVPs, venular branching asymmetry factor and arteriolar length-to-diameter ratio, were also higher in healthy individuals with high plaque burden $(P=0.01$ and $P=0.02$ respectively, after false discovery rate adjustment). Retinal photographic analysis shows potential as an adjunct for early detection of $A D$ or monitoring of $A D$-progression or response to treatments.

Translational Psychiatry (2013) 3, e233; doi:10.1038/tp.2012.150; published online 26 February 2013

\section{Introduction}

The primary neuropathological hallmark of Alzheimer's Disease (AD) is the presence of cerebral amyloid deposits (plaques). The disease leads to cerebral (cortical and particularly hippocampal) atrophy and is identified clinically by a progressive decline in memory, learning and executive function. In addition, the disease imposes a huge social and economic burden on society.

Although post-mortem examination of the brain is required for confirmation of $A D$, a diagnosis of 'probable $A D$ ' can be made in patients, fulfilling the criteria set down by the National Institute of Neurological and Communicative Disorders and Stroke/Alzheimer's Disease and Related Disorders Association $A D .{ }^{1}$ Currently, a diagnosis of probable AD is only possible when the condition has progressed, and considerable neurological damage has already occurred. The increasing prevalence of $A D$ in the population, along with the need to treat the disease before the brain is irreversibly damaged, calls for a sensitive and specific screening technology to identify high-risk individuals before cognitive symptoms arise. Although current treatments are limited in their efficacy, earlier detection of AD would assist the development of interventions aimed at preventing or delaying the neurodegenerative process, and could contribute to development and evaluation of new treatments.

Candidates for $\mathrm{AD}$ diagnostic or prognostic biomarkers are being sought from many fields including genetics, blood biomarkers, cerebrospinal fluid (CSF) proteomics and neuroimaging. ${ }^{2-11}$ One major genetic risk factor for sporadic $A D$ has been known for some time, the Apolipoprotein E e4 allele $(A P O E \epsilon 4){ }^{5}$ Two biomarkers are showing particular promise, firstly, CSF concentrations of $\beta$ amyloid $(A \beta)$, total $\tau$ and phosphorylated $\tau$ peptides, ${ }^{6,7,11,12}$ and secondly, brain $A \beta$ plaques imaged using Positron Emission Tomography (PET) with $\mathrm{C}-11 \mathrm{PiB}$ or $\mathrm{F} 18$ ligands. ${ }^{7,9-11}$ However, although these are valuable diagnostic and secondary screening biomarkers, they are not suited to population screening.

Cortical amyloid plaque burden can be evaluated in vivo using PET neuroimaging with injected ligands such as Pittsburgh compound-B (PiB), which selectively bind to $A \beta$ plaques. $^{7,9-11}$ PET-PiB imaging studies have revealed that not only do AD-diagnosed individuals exhibit high PiB

\footnotetext{
${ }^{1}$ Commonwealth Scientific and Industrial Research Organisation (CSIRO), Perth, WA, Australia; ${ }^{2}$ Preventative Health Flagship, Australian e-Health Research Centre, Perth, WA, Australia; ${ }^{3}$ School of Psychiatry and Clinical Neurosciences, University of Western Australia, Perth, WA, Australia; ${ }^{4}$ Centre of Excellence for Alzheimer's Disease Research and Care, School of Medical Sciences, Edith Cowan University, The McCusker Alzheimer's Research Foundation, Hollywood Medical Centre, Perth, WA, Australia; ${ }^{5}$ CSIRO Preventative Health Flagship, Australian e-Health Research Centre, Brisbane, QLD, Australia; ${ }^{6}$ Department of Nuclear Medicine and Centre for PET, Austin Health, Melbourne, VIC, Australia; ${ }^{7}$ The Mental Health Research Institute (MHRI), University of Melbourne, Melbourne, VIC, Australia; ${ }^{8} \mathrm{CSIRO}$ Preventative Health Flagship, materials Science and Engineering, Melbourne, VIC, Australia; ${ }^{9}$ National Ageing Research Institute, Melbourne, VIC, Australia; ${ }^{0}$ Department of Psychiatry, University of Melbourne, Melbourne, VIC, Australia and ${ }^{11}$ Australian Imaging, Biomarker and Lifestyle (AIBL) Study, Melbourne, VIC, Australia Correspondence: Professor RN Martins, Centre of Excellence for Alzheimer's Disease Research and Care, School of Medical Sciences, Edith Cowan University, The McCusker Alzheimer's Research Foundation, Suite 22, Hollywood Medical Centre, 85 Monash Avenue, Nedlands, Perth, WA 6009, Australia.
}

E-mail: ralph.n.martins@gmail.com

Keywords: Alzheimer's; retina; eye; aging; screening; vasculature

Received 21 September 2012; revised 26 November 2012; accepted 2 Decemeber 2012 
retention, but also $\sim 30 \%$ of cognitively normal elderly individuals. ${ }^{7-9}$ High $\mathrm{PiB}$ retention is associated with progression to symptomatic $\mathrm{AD},{ }^{10}$ hence evidence is building that PET-PiB imaging provides a test to identify preclinical AD. ${ }^{9,13,14}$ Indeed research suggests that plaque burden can be detected $\sim 15$ years before cognitive symptoms arise. ${ }^{9}$ PET imaging has become highly useful for $A D$ research purposes, but due to the expense of the procedure and the limited availability of PET facilities, it is not likely to become a suitable primary screening technology for AD.

The absence of a suitable screening technology for AD has motivated some researchers to look for biomarkers that might exist elsewhere in the body, including the eye (see review ${ }^{15}$ ). The retina is a developmental outgrowth of the brain and is often referred to as nature's brain slice as its laminar structure of neural tissue can easily be imaged in vivo. Alzheimer's pathology in the retina could be a potential screening measure, particularly since visual disturbance has often been detected as an early complaint of AD patients. ${ }^{16,17}$ In addition, many studies have reported reduced visual performance in AD. ${ }^{17-33}$ However, as none of these visual deficiencies are specific to $A D$, a newer field of research is investigating the hypothesis that there might be specific pathological changes in the eye that accompany the disease. There is hope that the eye might yet yield biomarkers that are either highly specific for $A D$, or can contribute to an AD-specific risk-profile analysis, in combination with genetic, blood and/or other tests.

Retinal morphology reported in $A D$ involves changes to the vasculature $^{34}$ and optic disc (optic nerve head), ${ }^{35-38}$ retinal cell loss ${ }^{31,39-43}$ and thinning of the retinal nerve fiber layer. ${ }^{34,44-46}$ The only study reporting retinal vascular changes in $A D$ was a small participant study by Berisha et al. ${ }^{34}$ finding that $A D$ participants had narrower blood column diameter in the major superior temporal retinal venule and decreased blood flow in this venule. These findings were made with the use of a laser Doppler device; no study to date has verified retinal vascular changes in $A D$ using retinal photography, which is more widely available. Detection of retinal vascular changes in $A D$ using retinal photography could lead to a more practically applicable AD screening test.

Advances in digital retinal imaging have facilitated accurate and reliable measurements of the optimality of the retinal vasculature. This includes vascular attenuation, branching geometry and measures of how effectively the vascular network fills the retinal space. The present study investigated whether vascular analysis of retinal photographs could identify any retinal vascular parameters (RVPs) that may be altered in AD. An additional question that was addressed by this study was whether retinal changes occur late in the disease process when $A D$ is clinically diagnosed or earlier in the disease process and therefore have prognostic potential before conventional diagnosis is possible.

\section{Methods}

Participants. Participants for the retina study were recruited from the Australian Imaging, Biomarkers and Lifestyle (AIBL) study of ageing. A full description of the AIBL cohort is reported elsewhere. ${ }^{47}$ AIBL participants were excluded from the retinal screening study if they had history or evidence of glaucoma, significant cataract or cataract surgery within the prior 6 months. All retina study participants were white Caucasians.

The AD participants fulfilled the National Institute of Neurological and Communicative Disorders and Stroke/ Alzheimer's Disease and Related Disorders Association criteria for probable AD. ${ }^{1}$ To address possible undiagnosed hypertension in this study, the definition of hypertension was extended to include both physician-diagnosed and identified by elevated blood pressure (systolic pressure $>140 \mathrm{~mm} \mathrm{Hg}$ or diastolic pressure $>90 \mathrm{~mm} \mathrm{Hg}$ ) on the day of retinal imaging.

Neuroimaging methodology is reported elsewhere. ${ }^{48}$ Briefly, participants were neuroimaged for the presence of fibrillar brain amyloid using PET-PiB. ${ }^{49,50} \mathrm{~A}$ bimodal distribution of PET-PiB Standardized Uptake Value Ratio (SUVR) was observed in the healthy control $(\mathrm{HC})$ group of the AIBL study. ${ }^{51}$ Consequently, hierarchical cluster analysis yielded a cutoff for neocortical SUVR of 1.5, separating high from low plaque burden. ${ }^{51}$ Subjects were classified as $\mathrm{PiB}$ negative $(\mathrm{HC}-)$ if their neocortex SUVR was $<1.5$, and $\mathrm{PiB}$ positive $(\mathrm{HC}+)$ if their neocortex SUVR was $>1.5$.

All participants or legal guardians provided their written informed consent, and all retinal imaging experiments were approved by the Ethics Committee of the University of Western Australia, according to the Helsinki Declaration. The Ethics approval for the parent AIBL study was obtained from the Austin Health Human Research Ethics Committee and the Hollywood Private Hospital Ethics Committee.

In total, 148 participants entered the retinal vascular parameter study (123 healthy control and 25 AD). The study had two components: (i) a 'clinical status study' investigating RVP differences between the $25 \mathrm{AD}$ and $123 \mathrm{HC}$ participants, and (ii) a 'neuroimaging study' investigating RVP with respect to neocortical plaque burden in $\mathrm{HC}$ participants with $\mathrm{AIBL}$ neuroimaging data available $(n=45)$.

Retinal photography and grading. Digital retinal color photographs (disc centered, $45^{\circ}$ field) were collected with a Canon CR-1 non-mydriatic camera (Canon USA, Lake Success, NY, USA) in a darkened room. Retinal photographs were analyzed with Singapore I Vessel Assessment (SIVA) semiautomated software from the Singapore Eye Research Institute. The analytical principles and reproducibility of measurements using the SIVA software have been described previously. ${ }^{52}$ Briefly, the RVPs were measured from the width and branching geometry of the retinal vessels. Nineteen RVPs were calculated for each retinal photograph (see Table 1 for a description of RVPs).

The measured retinal zones of interest for the RVPs were 0.5-1.0 disc diameters away from the disc margin (zone B, Figure 1) or 0.5-2.0 disc diameters away from the disc margin (zone C, Figure 1). Measurement in these zones ensured that the vessels had attained arteriolar status. The measured zone for each parameter is listed in Table 1. Trained graders followed a standardised protocol and performed corrections to automated procedures as necessary.

Vascular calibers were calculated for the six largest arterioles and six largest venules. Standard deviation of the width in zone B (BSTD) was calculated for the arteriolar and 
Table 1 Description of the 19 retinal vascular parameters (RVPs) measured for each retinal photograph, along with the retinal zone of interest (see Figure 1) for calculation of each parameter

\begin{tabular}{|c|c|c|}
\hline Parameter & Description & $\begin{array}{l}\text { Retinal } \\
\text { zone }\end{array}$ \\
\hline CRAE & Central retinal arteriolar equivalent caliber & $\mathrm{B}$ \\
\hline CRVE & Central retinal venular equivalent caliber & $\mathrm{B}$ \\
\hline AVR & Arteriole-venular Ratio (CRAE/CRVE) & $\mathrm{B}$ \\
\hline FDa & Fractal dimension of arteriolar network & $\mathrm{C}$ \\
\hline FDv & Fractal dimension of venular network & $\mathrm{C}$ \\
\hline BSTDa & Zone B standard deviation Arteriole & $\mathrm{B}$ \\
\hline BSTDV & Zone B standard deviation Venule & $\mathrm{B}$ \\
\hline TORTa & Curvature tortuosity arteriole & $\mathrm{C}$ \\
\hline TORTV & Curvature tortuosity venule & $\mathrm{C}$ \\
\hline Num1stBa & Number of first branching arterioles & C \\
\hline Num1stBv & Number of first branching venules & $\mathrm{C}$ \\
\hline $\mathrm{BCa}$ & Branching coefficient arteriole & $\mathrm{C}$ \\
\hline $\mathrm{BCv}$ & Branching coefficient venule & $\mathrm{C}$ \\
\hline $\mathrm{AFa}$ & $\begin{array}{l}\text { Asymmetry factor arteriole (or asymmetry } \\
\text { ratio) }\end{array}$ & C \\
\hline AFv & $\begin{array}{l}\text { Asymmetry factor venule (or asymmetry } \\
\text { ratio) }\end{array}$ & $\mathrm{C}$ \\
\hline JEa & Junctional exponent deviation for arterioles & C \\
\hline JEv & Junctional exponent deviation for venules & $\mathrm{C}$ \\
\hline LDRa & Length diameter ratio arteriole & C \\
\hline LDRv & Length diameter ratio venule & C \\
\hline
\end{tabular}

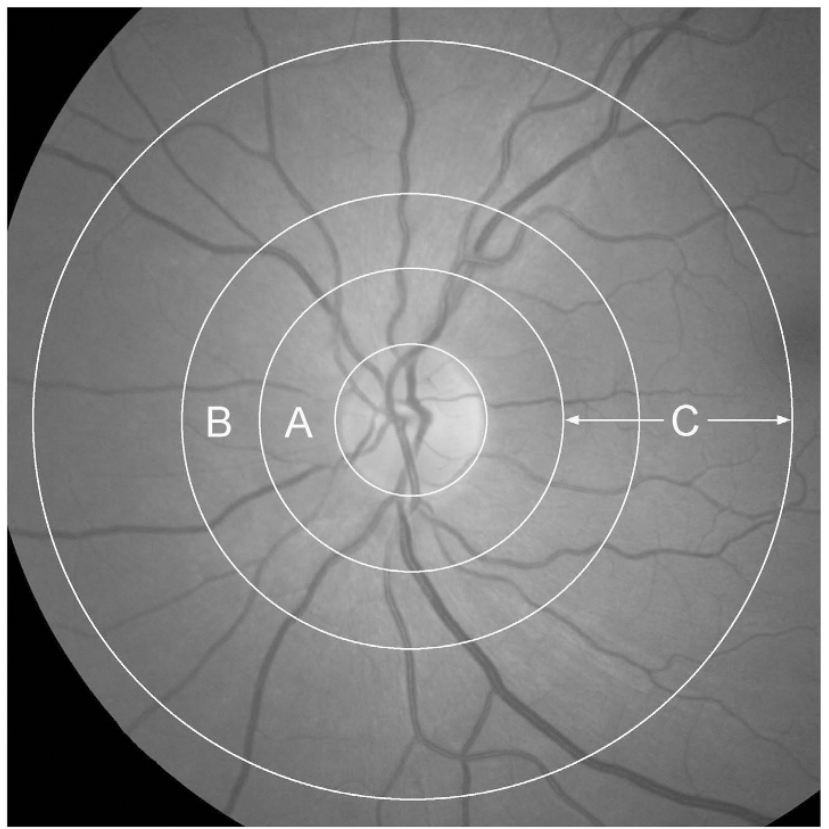

Figure 1 Retinal zones utilized for retinal vascular analysis. Zone $A$ is defined as the region from 0 to 0.5 disc diameters away from the disc margin, zone $B$ is defined as the region from 0.5 to 1.0 disc diameters away from the disc margin and zone $\mathrm{C}$ is defined as the region from 0.5 to 2.0 disc diameters away from the disc margin. Retinal photograph from a healthy individual.

venular networks. Summary measures of vascular equivalent caliber were also calculated (central retinal arterial (CRAE) and venular (CRVE) equivalent caliber), based on the improved Knudston-Parr-Hubbard formula. ${ }^{53,54}$ CRAE and CRVE represent the equivalent single-vessel parent caliber (width) for the six arterioles and venules respectively. From these indices, the arteriole-to-venule ratio (AVR) was calculated (AVR $=$ CRAE/CRVE).

Natural patterns such as vessel networks often exhibit fractal properties, whereby they appear the same when viewed over a range of magnifications. The fractal dimension (FD) describes the range of scales over which this selfsimilarity is observed. In this study, the fractal dimension of the retinal vascular network was calculated using the boxcounting method. ${ }^{55}$ Larger values reflect a more complex branching pattern.

Retinal vascular tortuosity is defined as the integral of the curvature squared along the path of the vessel, normalized by the total path length. ${ }^{56}$ All vessels in the zone of interest with a width $>40 \mu \mathrm{m}$ were measured. The estimates were summarized as the average tortuosity of the measured vessels. A smaller tortuosity value indicates straighter vessels.

The number of vessels with a first bifurcation (branch) in zone C (Num1stB) was counted. Average metrics of these branches were then calculated; branching coefficient (BC), asymmetry factor (AF) and junctional exponent deviation (JE). The branching coefficient at each vascular bifurcation is defined as $B C=\left(D 1^{2}+D 2^{2}\right) /\left(D 0^{2}\right)$, where $D 1$ and $D 2$ are the mean vessel widths of each daughter vessel and D0, the mean width of the parent vessel. The AF is defined as AF = $\left(D 1^{2}\right) /\left(D 2^{2}\right)$ (where $\left.D 1 \geqslant D 2\right)$. JE expresses the deviation from optimality of the ratio of vessel widths at a bifurcation. ${ }^{57}$ It is defined as $\mathrm{JE}=\left(\mathrm{D} 0^{3}-\left(\mathrm{D} 1^{3}+\mathrm{D} 2^{3}\right)\right)^{1 / 3} / \mathrm{D} 0$. In terms of minimizing shear stress and work over a bifurcation, the optimum values for $\mathrm{BC}$ and $\mathrm{JE}$ are $\mathrm{BC}=2^{1 / 3}=1.26$ and $\mathrm{JE}=0$. All vessels with their first bifurcation within the measured zone were analyzed, with the average value for all vessels reported.

LDR is defined as the vessel length from the midpoint of one vascular bifurcation to the midpoint of the next bifurcation, expressed as a ratio to the diameter of the parent vessel at the first bifurcation. ${ }^{58}$ For all RVP names, a lowercase 'a' or ' $v$ ' at the end of the name indicates a measurement of the arteriolar or venular network respectively.

Statistical analysis. Demographic comparisons were performed using a $\chi^{2}$ test for categorical variables (gender, hypertension, diabetes, smoking status and $A P O E \epsilon 4$ carrier status), and analysis of variance (ANOVA) for the continuous age variable $(P<0.05$ considered significant)

Across-group RVP scores were compared using analysis of variance (ANCOVA), correcting for confounders (age, gender, hypertension, diabetes, smoking status and $A P O E \epsilon 4$ carrier status). The likelihood of false positive results was minimized by adjusting $P$-values according to the Benjamini and Hochberg false discovery rate (FDR) method. ${ }^{59}$

Receiver-operating characteristic (ROC) curve analysis was also performed to further illustrate the classification accuracy of the RVPS. The area under the curve (AUC) of the ROC curves was calculated; an AUC of 1 indicates perfect classification ability into AD or $\mathrm{HC}$, whereas an AUC near 0.5 indicates poor (random) classification ability. Logistical models combining RVPs were created to assess combined classification performance. 
All statistical analyses were conducted in XLstat 2011 (Microsoft Excel).

\section{Results}

Clinical status study. The clinical status cohort consisted of 25 probable AD patients (age $72.4 \pm 7.5$ years, 12 male and 13 female individuals) and 123 healthy control participants (age $71.6 \pm 5.6$ years, 55 male and 68 female individuals). The demographics of this cohort are presented in Table 2. Comorbid medical conditions considered relevant to retinal vascular changes were hypertension and diabetes mellitus. Participant-reported smoking (current or past history of) was also considered due to previous reports linking smoking with possible retinal vascular changes. ${ }^{60} \mathrm{HC}$ and AD groups did not differ significantly in age, gender, hypertension, diabetes or smoking status. There was a higher percentage of $A P O E \epsilon 4$ carriers in the $A D$ group $(P=0.019)$.

After FDR adjustment, significant differences in 13 of 19 RVPs were found between the AD and HC groups (Table 2 and Figure 2). Logistical models combining parameters were created for combined AD classification. A logistic model combining these 13 RVP's provided good classification performance (81.2\% sensitivity, $75.7 \%$ specificity and $87.7 \%$ AUC), compared with the logistic model including only age and $A P O E \in 4$ carrier status $(68.0 \%$ sensitivity, $61.8 \%$ specificity and $63.7 \%$ AUC).

Neuroimaging study. AIBL neuroimaging data was available for $45 \mathrm{HC}$ participants. This neuroimaging cohort was grouped according to high (SUVR $>1.5$ ) or low (SUVR $<1.5$ ) neocortical amyloid plaque burden $(\mathrm{HC}+$ and $\mathrm{HC}-$ respectively). The demographics of the neuroimaging cohort are presented in Table 3. There were 15 participants in the $\mathrm{HC}+$ group and 30 participants in the $\mathrm{HC}-$ group. The $\mathrm{HC}+$ group had a higher percentage of $A P O E \epsilon 4$ carriers than the $\mathrm{HC}-$ group $(P=0.04)$; there were no significant differences in the other demographic variables.

ANCOVA analysis revealed larger venular branching asymmetry factor (AFv) and arteriolar length-to-diameter ratio (LDRa) in the $\mathrm{HC}+$ group $(P=0.01$ and $P=0.02$ respectively, after FDR adjustment, see Figure 2D). These two parameters were also larger in $A D$ compared with $\mathrm{HC}$, hence these results are consistent with the hypothesis that RVP changes may precede AD diagnosis.

Combined in a logistic model, AFv and LDRa could identify high plaque burden in the $\mathrm{HC}$ group with $76.9 \%$ sensitivity, $69.2 \%$ specificity and $74.6 \%$ AUC. When combined with age and $A P O E \in 4$ carrier status, the classification performance improved to $84.7 \%$ sensitivity, $69.2 \%$ specificity and $82.8 \%$ AUC (compared with a logistic model with only age and APOE $\epsilon 4$ carrier status; $66.7 \%$ sensitivity, $73.3 \%$ specificity and $73.8 \%$ AUC).

\section{Discussion}

This study has demonstrated retinal vascular abnormalities in $A D$, and has found an association between some retinal abnormalities and neocortical amyloid plaque burden. The results indicate that retinal photography might provide a sensitive method (or adjunct to blood or other tests) for detecting preclinical $A D$, allowing the possibility of population screening.

Table 2 Demographics and descriptive RVP analysis for HC and AD groups, with ANCOVA and ROC analysis

\begin{tabular}{|c|c|c|c|c|c|}
\hline & Healthy control & Alzheimer's disease & P-value & FDR adj. $\mathrm{P}$ & ROC: $A U C \%$ (s.d.\%) \\
\hline Number of participants $(\mathrm{N})$ & 123 & 25 & & & \\
\hline Age: years (mean (s.d.)) & $71.6(5.6)$ & $72.4(7.5)$ & $0.557^{\mathrm{a}}$ & & \\
\hline Gender; Males: (N (\%)) & $55(45)$ & $12(48)$ & $0.764^{b}$ & & \\
\hline Hypertension: (N (\%)) & $44(36)$ & $11(44)$ & $0.439^{b}$ & & \\
\hline Diabetes: $(\mathrm{N}(\%))$ & $6(5)$ & $2(8)$ & $0.533^{b}$ & & \\
\hline History of Smoking: (N(\%)) & $5(4)$ & $2(8)$ & $0.407^{b}$ & & \\
\hline APOE $€ 4$ Carrier: (N (\%)) & $38(31)$ & $14(56)$ & $0.019^{b}$ & & \\
\hline CRVE (mean (s.d.)) & $182.7(15.8)$ & $169.7(15.3)$ & $0.000256^{c}$ & $0.0049^{d}$ & $0.703(0.067)$ \\
\hline FDv (mean (s.d.)) & $1.210(0.05)$ & $1.171(0.048)$ & $0.000350^{c}$ & $0.0033^{d}$ & $0.716(0.074)$ \\
\hline BSTDa (mean (s.d.)) & $4.101(0.504)$ & $4.538(0.984)$ & $0.00135^{c}$ & $0.0086^{\mathrm{d}}$ & $0.595(0.070)$ \\
\hline BSTDV (mean (s.d.)) & $3.983(0.575)$ & $4.433(1.333)$ & $0.00188^{\mathrm{C}}$ & $0.0089^{d}$ & $0.541(0.081)$ \\
\hline Num1stBv (mean (s.d.)) & $3.618(1.052)$ & $2.960(1.136)$ & $0.00560^{c}$ & $0.021^{\mathrm{d}}$ & $0.660(0.121)$ \\
\hline Num1stBa (mean (s.d.)) & $3.675(1.075)$ & $3.040(0.978)$ & $0.00710^{\mathrm{C}}$ & $0.022^{d}$ & $0.675(0.142)$ \\
\hline FDa (mean (s.d.)) & $1.235(0.052)$ & $1.201(0.061)$ & $0.00799^{c}$ & $0.021^{d}$ & $0.644(0.075)$ \\
\hline CRAE (mean (s.d.) & $129.1(10.3)$ & $122.9(12.4)$ & $0.0115^{\mathrm{c}}$ & $0.027^{d}$ & $0.612(0.082)$ \\
\hline $\mathrm{AFa}$ (mean (s.d.)) & $0.778(0.086)$ & $0.824(0.081)$ & $0.0176^{\mathrm{C}}$ & $0.037^{d}$ & $0.578(0.081)$ \\
\hline BCv (mean (s.d.)) & $1.253(0.165)$ & $1.347(0.240)$ & $0.0186^{\mathrm{C}}$ & $0.035^{d}$ & $0.556(0.084)$ \\
\hline Tortv $\left(\times 10^{-5}\right)($ mean $($ s.d. $))$ & $7.660(1.554)$ & $6.952(2.601)$ & $0.0244^{\mathrm{C}}$ & $0.042^{d}$ & $0.706(0.073)$ \\
\hline AFv (mean (s.d.)) & $0.701(0.097)$ & $0.748(0.095)$ & $0.0301^{\mathrm{c}}$ & $0.047^{d}$ & $0.616(0.074)$ \\
\hline LDRa (mean (s.d.)) & $17.05(7.87)$ & $21.72(9.55)$ & $0.0333^{\mathrm{C}}$ & $0.049^{d}$ & $0.651(0.068)$ \\
\hline JEv (mean (s.d.)) & $-0.110(0.378)$ & $-0.272(0.338)$ & $0.0483^{C}$ & $0.066^{d}$ & $0.539(0.074)$ \\
\hline
\end{tabular}

Only RVPs that were significantly different between groups $(P<0.05)$ in ANCOVA analysis are shown. Significant results after FDR adjustment shown in bold type. Classification accuracy of RVP parameters from ROC analysis, AUC (area under the curve): AUC $=0.5$ implies random separation of groups, AUC $=1.0$ implies perfect separation.

Refer to Table 1 for a description of the retinal vascular parameters. APOE $\epsilon 4$ carrier status refers to carrier/non-carrier of an Apolipoprotein $\mathrm{E}$ e 4 allele.

${ }^{a}$ Analysis of variance (ANOVA) for the continuous age demographic variable $\left(P<0.05\right.$ considered significant). ${ }^{b} \chi^{2}$ test for categorical demographic variables (gender, hypertension, diabetes, smoking status and $A P O E \epsilon 4$ carrier status) $\left(P<0.05\right.$ considered significant). ${ }^{\mathrm{C}} P$-value from ANCOVA analysis of differences between groups (including confounders). ${ }^{d}$ ANCOVA $P$-values adjusted for false discovery rate (FDR) $(P<0.05$ considered significant). 
a

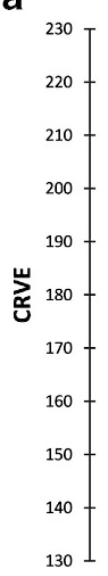

C

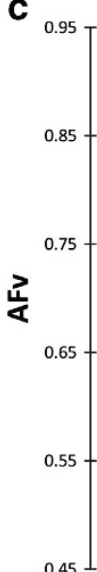

$\mathrm{p}<0.005$

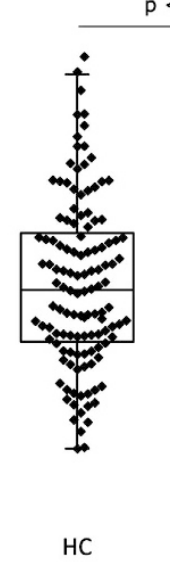

$p<0.05$

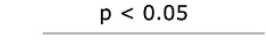

$\mathrm{HC}-$

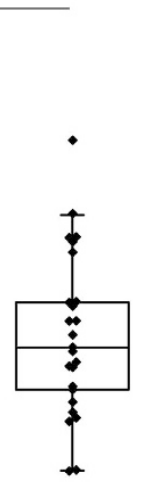

$\mathrm{AD}$

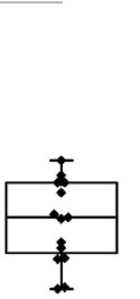

b

$$
{ }_{1.35}^{1.35}
$$

d

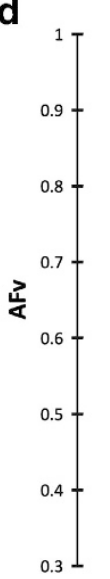

$\mathrm{p}<0.005$
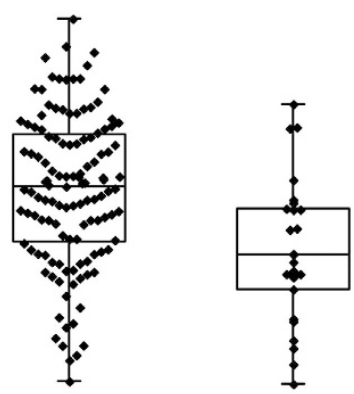

AD

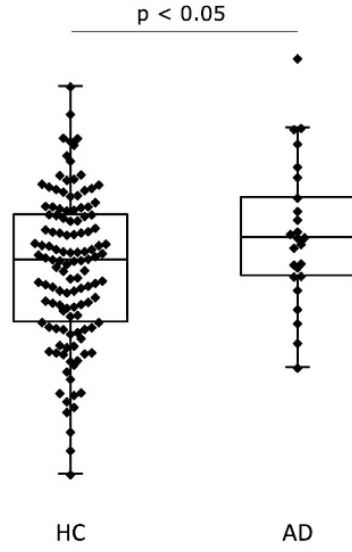

Figure 2 Boxplot comparison of (a) Central retinal venular equivalent caliber (CRVE), (b) Fractal dimension of the venular network (FDv) and (c) Asymmetry factor of the venular network (AFv) across $\mathrm{HC}(n=123)$ and $\mathrm{AD}(n=25)$ groups. The $\mathrm{HC}$ group includes individuals with high plaque burden $(\mathrm{HC}+)$, low plaque burden $(\mathrm{HC}-)$ and unknown plaque burden. AFv is also compared across $\mathrm{HC}-(n=30)$ and $\mathrm{HC}+(n=15)$ subgroups (d).

Table 3 Demographics of the neuroimaging subgroups

\begin{tabular}{lccc}
\hline & $H C-$ & $H C+$ & P-value \\
\hline Number of participants: (N) & 30 & 15 & \\
Age: years (mean (s.d.)) & $70.4(5.3)$ & $73.7(6.3)$ & $0.08^{\mathrm{a}}$ \\
Gender; Males: (N (\%)) & $15(50)$ & $9(60)$ & $0.53^{\mathrm{b}}$ \\
n(hypertension) & $11(37)$ & $6(40)$ & $0.52^{\mathrm{b}}$ \\
n(diabetes) & $1(3)$ & $2(13)$ & $0.99^{\mathrm{b}}$ \\
n(smokers) & $2(7)$ & $0(0)$ & $0.99^{\mathrm{b}}$ \\
APOE $\epsilon 4$ carrier: (N (\%)) & $14(47)$ & $12(75)$ & $\mathbf{0 . 0 4 ^ { \mathrm { b } }}$ \\
\hline
\end{tabular}

$\mathrm{HC}-$ : healthy controls with low plaque burden, $\mathrm{HC}+$ : healthy controls with high plaque burden. s.d.: standard deviation. No demographic was significantly different between groups. Significant results in bold type.

${ }^{a}$ Analysis of variance (ANOVA) for the continuous age demographic variable $\left(P<0.05\right.$ considered significant). ${ }^{\mathrm{b}} \chi^{2}$ test for categorical demographic variables (gender, hypertension, diabetes, smoking status and APOE $€ 4$ carrier status) $(P<0.05$ considered significant).

Many studies have reported retinal degeneration in $A D$, particularly thinning of the retinal nerve fiber layer and loss of ganglion cells. However, only one previous study has reported retinal vascular abnormalities in $A D$, involving thinning of the major superior temporal venule blood column diameter and reduced blood flow in this vessel, using a laser Doppler device. ${ }^{34}$ Retinal photography is a more widely available technology for investigating the retina, with eye clinics and many optometrists now utilizing the technique to provide regular retinal health checks. In addition, advances in digital retinal imaging have facilitated accurate and reliable measurements of the optimality of the retinal vasculature. To the authors' knowledge, this is the first study to report retinal vascular abnormalities in $A D$ using retinal photography.

The retinal vascular abnormalities found in $A D$ in the present study can be broadly summarized as: (1) vascular attenuation (CRVE, CRAE and LDRa), (2) increasing standard deviation of vessel widths (BSTD), (3) reduced complexity of the branching pattern (FD, Num1stB), (4) reduced optimality of the branching geometry (AF, BCv) and (5) less tortuous venules (Tortv). These findings add to the growing evidence that retinal changes occur in AD. We demonstrate for the first time that these changes can be detected using noninvasive, readily available retinal photography. Models combining RVPs perform well at distinguishing diagnosed $A D$ patients from healthy controls. However these models are optimized for the present data set and should be tested on other cohorts in future. 
An additional question addressed by the present study was whether these changes occur late in the disease process when $A D$ is clinically diagnosed, or earlier in the disease process, providing prognostic potential before conventional diagnosis is possible. To address this question, RVPs were compared between healthy individuals with high $(\mathrm{HC}+)$ and low $(\mathrm{HC}-)$ neocortical plaque burden. High plaque burden is predictive of progression to $A D,{ }^{9,13,14}$ so the $\mathrm{HC}+$ group is believed to represent those participants in the preclinical stage of $A D$.

Two of the RVPs that were found to be elevated in $A D$, venular branching AFv and LDRa, were also higher in the $\mathrm{HC}+$ group compared with the $\mathrm{HC}-$ group. These results indicate that changes to retinal vascular widths and branching may be occurring early in $A D$ pathogenesis, during the asymptomatic plaque deposition stage before subsequent cognitive decline. Hence, retinal photography combined with vascular analysis indicates potential as an adjunct to detect preclinical AD.

Our findings indicate a relationship between RVPs, neocortical amyloid plaque load and AD. It is of interest to evaluate the possible pathophysiological basis of these results. Although cerebral amyloid plaques and neurodegeneration (particularly hippocampal) are the main hallmarks of $A D$, cerebral vascular changes are also known to occur in the disease. In particular, vascular disease was also evident in the original and disease defining cases of Alzheimer ${ }^{61}$ and cerebral amyloid angiopathy, characterized by deposition of amyloid in vessel walls, has been well documented in AD. ${ }^{62-64}$ Given the homology between the retinal and cerebral microvasculature, ${ }^{65}$ concomitant amyloid angiopathy in AD might extend to the retina, with associated destruction of the vessel walls, resulting in changes to vascular widths and topology.

As vascular changes and neurodegeneration appear to be occurring in both the brain and retina in $A D$, there is some suggestion that $A D$-specific pathology could also be occurring in the retina. Fascinatingly, preliminary evidence is emerging that $A \beta$ plaques may occur in the human $A D$ retina, ${ }^{66}$ possibly providing a more accessible location to assess AD-specific neuropathology. However, further research is needed to determine the nature of these retinal plaques and their relationship with $\mathrm{AD}$ and possible concomitant ocular disease. In addition, potential relationships between retinal degeneration reported in $A D,{ }^{31,34-46}$ retinal $A \beta$ plaques and the retinal vascular changes reported in the present study are intriguing, but require further investigation.

Interestingly, a previous study examining RVPs in dementia reported that wider retinal venules are associated with an increased risk of vascular dementia. ${ }^{67}$ As AD and vascular dementia are the most common forms of dementia, our contrasting results demonstrating lower venular caliber in $A D$ encourage further research into retinal vascular changes that show potential to discriminate between these forms of dementia.

Hypertension is a significant risk factor for $A D$ and causes arteriolar narrowing and venular widening in the retinal circulation. ${ }^{60}$ Some studies have reported that these vascular changes may precede clinical hypertension, ${ }^{68,69}$ a possibility that must be considered in this study. However, the opposing results for CRVE in hypertension and AD suggest that this is unlikely to be the cause of the observed results. Although, FD has been found to be lower in nonproliferative diabetic retinopathy of the macular region, ${ }^{70,71}$ all diabetic participants in the present study were controlled and did not exhibit diabetic retinopathy.

Measurements of ocular refractive error were not available for this study. Dimensional parameters (CRAE, CRVE and BSTD) were therefore subject to refractive error, unlike the remaining RVPs which are dimensionless. Bias from magnification differences is not profound in most eyes within the refractive power range of \pm 3 diopter $^{72}$ and refractive errors are not likely to be associated with $A D$ and hence are unlikely to confound the associations assessed. The vessel width reduction observed in $A D$, in contrast with the increase in the standard deviation of vessel widths, lends support to vessel width changes in $A D$ that are independent of magnification effects, as magnification effects alone would be expected to influence both parameters in the same manner. It is possible that vessel narrowing in AD affects vessels selectively, hence increasing the standard deviation of vessel widths.

The major limitation of this study is the size of the AD and neuroimaging cohorts. Future studies with larger cohorts are needed to further examine associations between RVPs and $A D$ or neocortical plaque burden. The major strength of the study are the well-characterized cohorts, including neuroimaging data that enable deeper interrogation of associations between RVPs and AD.

The results of the present study indicate that retinal photography combined with vascular analysis might provide an adjunct for detecting preclinical $A D$, or for monitoring disease progression and response to intervention. The study also found retinal abnormalities in $A D$ that oppose those previously reported in vascular dementia, suggesting potential for retinal vascular analysis to distinguish between these most common forms of dementia. Natural variation in RVPs between individuals may limit the utility of a single retinal photography screening test for $A D$, hence it is possible that retinal monitoring, allowing longitudinal analysis of retinal changes, might facilitate more accurate preclinical detection or monitoring of AD. Future longitudinal studies are planned to further explore this possibility and to determine the time course of retinal changes in AD.

\section{Conflict of interest}

The authors declare no conflict of interest.

Acknowledgements. We would like to acknowledge the altruism of the participants and their families and the contributions of the McCusker Alzheimer's Research Foundation research and support staff for their contributions to this study.

1. McKhann G, Drachman D, Folstein M, Katzman R, Price D, Stadlan EM. Clinical diagnosis of Alzheimer's disease: report of the NINCDS-ADRDA Work Group under the auspices of Department of Health and Human Services Task Force on Alzheimer's Disease. Neurology 1984; 34: 939-944.

2. Harold D, Abraham R, Hollingworth P, Sims R, Gerrish A, Hamshere ML et al. Genomewide association study identifies variants at CLU and PICALM associated with Alzheimer's disease. Nat Genet 2009; 41: 1088-1093.

3. Lambert JC, Heath S, Even G, Campion D, Sleegers K, Hiltunen M et al. Genome-wide association study identifies variants at CLU and CR1 associated with Alzheimer's disease. Nat Genet 2009; 41: 1094-1099. 
4. Bertram L, Tanzi RE. Thirty years of Alzheimer's disease genetics: the implications of systematic meta-analyses. Nat Rev Neurosci 2008; 9: 768-778.

5. Corder EH, Saunders AM, Strittmatter WJ, Schmechel DE, Gaskell PC, Small GW et al. Gene dose of apolipoprotein E type 4 allele and the risk of Alzheimer's disease in late onset families. Science 1993; 261: 921-923.

6. Sunderland T, Linker G, Mirza N, Putnam KT, Friedman DL, Kimmel LH et al. Decreased beta-amyloid1-42 and increased tau levels in cerebrospinal fluid of patients with Alzheimer disease. JAMA 2003; 289: 2094-2103.

7. Fagan AM, Mintun MA, Mach RH, Lee SY, Dence CS, Shah AR et al. Inverse relation between in vivo amyloid imaging load and cerebrospinal fluid Abeta42 in humans. Ann Neurol 2006; 59: 512-519.

8. Rowe CC, Ng S, Ackermann U, Gong SJ, Pike K, Savage G et al. Imaging beta-amyloid burden in aging and dementia. Neurology 2007; 68: 1718-1725

9. Rowe CC, Ellis KA, Rimajova M, Bourgeat P, Pike KE, Jones $G$ et al. Amyloid imaging results from the Australian Imaging, Biomarkers and Lifestyle (AIBL) study of aging Neurobiol Aging 2010; 31: 1275-1283.

10. Morris JC, Roe CM, Grant EA, Head D, Storandt M, Goate AM et al. Pittsburgh compound $B$ imaging and prediction of progression from cognitive normality to symptomatic Alzheimer disease. Arch Neurol 2009; 66: 1469-1475.

11. Thal LJ, Kantarci K, Reiman EM, Klunk WE, Weiner MW, Zetterberg $\mathrm{H}$ et al. The role of biomarkers in clinical trials for Alzheimer disease. Alzheimer Dis Assoc Disord 2006; 20 : 6-15.

12. Blennow $\mathrm{K}$, Hampel $\mathrm{H}$, Weiner $\mathrm{M}$, Zetterberg $\mathrm{H}$. Cerebrospinal fluid and plasma biomarkers in Alzheimer disease. Nat Rev Neurol 2010; 6: 131-144.

13. Pike KE, Savage G, Villemagne VL, Ng S, Moss SA, Maruff $P$ et al. Beta-amyloid imaging and memory in non-demented individuals: evidence for preclinical Alzheimer's disease. Brain 2007; 130(Pt 11): 2837-2844

14. Sperling RA, Aisen PS, Beckett LA, Bennett DA, Craft S, Fagan AM et al. Toward defining the preclinical stages of Alzheimer's disease: recommendations from the National Institute on Aging-Alzheimer's Association workgroups on diagnostic guidelines for Alzheimer's disease. Alzheimers Dement 2011; 7: 280-292.

15. Frost $\mathrm{S}$, Martins RN, Kanagasingam Y. Ocular biomarkers for early detection of Alzheimer's disease. J Alzheimers Dis 2010; 22: 1-16.

16. Katz B, Rimmer S. Ophthalmologic manifestations of Alzheimer's disease. Surv Ophthalmol 1989; 34: 31-43.

17. Sadun AA, Borchert M, DeVita E, Hinton DR, Bassi CJ. Assessment of visual impairment in patients with Alzheimer's disease. Am J Ophthalmol 1987; 104: 113-120.

18. Trick GL, Trick LR, Morris $P$, Wolf M. Visual field loss in senile dementia of the Alzheimer's type. Neurology 1995; 45: 68-74.

19. Whittaker KW, Burdon MA, Shah P. Visual field loss and Alzheimer's disease. Eye (Lond) 2002; 16: 206-208.

20. Pache M, Smeets CH, Gasio PF, Savaskan E, Flammer J, Wirz-Justice A et al. Colour vision deficiencies in Alzheimer's disease. Age Ageing 2003; 32: 422-426.

21. Cronin-Golomb A, Sugiura R, Corkin S, Growdon JH. Incomplete achromatopsia in alzheimer's disease. Neurobiol Aging 1993; 14: 471-477.

22. Lakshminarayanan V, Lagrave J, Kean ML, Dick M, Shankle R. Vision in dementia: contrast effects. Neurol Res 1996; 18: 9-15.

23. Crow RW, Levin LB, LaBree L, Rubin R, Feldon SE. Sweep visual evoked potential evaluation of contrast sensitivity in Alzheimer's dementia. Invest Ophthalmol Vis Sci 2003 44: 875-878

24. Nissen MJ, Corkin S, Buonanno FS, Growdon JH, Wray SH, Bauer J. Spatial vision in Alzheimer's disease. General findings and a case report. Arch Neurol 1985; 42: 667-671.

25. Mendola JD, Cronin-Golomb A, Corkin S, Growdon JH. Prevalence of visual deficits in Alzheimer's disease. Optom Vis Sci 1995; 72: 155-167.

26. Schlotterer G, Moscovitch M, Crapper-McLachlan D. Visual processing deficits as assessed by spatial frequency contrast sensitivity and backward masking in normal ageing and Alzheimer's disease. Brain 1984; 107(Pt 1): 309-325.

27. Mielke R, Kessler J, Fink G, Herholz K, Heiss WD. Dysfunction of visual cortex contributes to disturbed processing of visual information in Alzheimer's disease. Int J Neurosci 1995; 82: 1-9.

28. Morrison $\mathrm{JH}$, Hof $\mathrm{PR}$, Bouras $\mathrm{C}$. An anatomic substrate for visual disconnection in Alzheimer's disease. Ann NY Acad Sci 1991; 640: 36-43.

29. Wong-Riley M, Antuono P, Ho KC, Egan R, Hevner R, Liebl W et al. Cytochrome oxidase in Alzheimer's disease: biochemical, histochemical, and immunohistochemical analyses of the visual and other systems. Vision Res 1997; 37: 3593-3608.

30. Gilmore GC, Wenk HE, Naylor LA, Koss E. Motion perception and Alzheimer's disease. J Gerontol 1994; 49: P52-P57.

31. Sadun AA, Bassi CJ. Optic nerve damage in Alzheimer's disease. Ophthalmology 1990; 97: $9-17$

32. Fletcher WA, Sharpe JA. Smooth pursuit dysfunction in Alzheimer's disease. Neurology 1988; 38: 272-277.

33. Mendez MF, Tomsak RL, Remler B. Disorders of the visual system in Alzheimer's disease J Clin Neuroophthalmol 1990; 10: 62-69.

34. Berisha F, Feke GT, Trempe CL, McMeel JW, Schepens CL. Retinal abnormalities in early Alzheimer's disease. Invest Ophthalmol Vis Sci 2007; 48: 2285-2289.

35. Tsai CS. Optic nerve head and nerve fiber layer in Alzheimer's disease. Arch Ophthalmol 1991; 109: 199
36. Danesh-Meyer HV, Birch H, Ku JY, Carroll S, Gamble G. Reduction of optic nerve fibers in patients with Alzheimer disease identified by laser imaging. Neurology 2006; 67: 1852-1854.

37. Bayer AU, Ferrari F, Erb C. High occurrence rate of glaucoma among patients with Alzheimer's Disease. Eur Neurol 2002; 47: 165-168.

38. Tamura H, Kawakami H, Kanamoto T, Kato T, Yokoyama T, Sasaki K et al. High frequency of open-angle glaucoma in Japanese patients with Alzheimer's disease. J Neurol Sci 2006; 246: $79-83$

39. Blanks JC, Hinton DR, Sadun AA, Miller CA. Retinal ganglion cell degeneration in Alzheimer's disease. Brain Res 1989; 501: 364-372.

40. Blanks JC, Schmidt SY, Torigoe Y, Porrello KV, Hinton DR, Blanks RH. Retinal pathology in Alzheimer's disease. II. Regional neuron loss and glial changes in GCL. Neurobiol Aging 1996; 17: 385-395.

41. Blanks JC, Torigoe Y, Hinton DR, Blanks RH. Retinal pathology in Alzheimer's disease. I. Ganglion cell loss in foveal/parafoveal retina. Neurobiol Aging 1996; 17: 377-384.

42. Hinton DR, Sadun AA, Blanks JC, Miller CA. Optic-nerve degeneration in Alzheimer's disease. N Engl J Med 1986; 315: 485-487.

43. Sadun AA, Bassi CJ. The visual system in Alzheimer's disease. Res Publ Assoc Res Nerv Ment Dis 1990; 67: 331-347.

44. Paquet C, Boissonnot M, Roger F, Dighiero P, Gil R, Hugon J. Abnormal retinal thickness in patients with mild cognitive impairment and Alzheimer's disease. Neurosci Lett 2007; 420: 97-99.

45. Parisi V, Restuccia R, Fattapposta F, Mina C, Bucci MG, Pierelli F. Morphological and functional retinal impairment in Alzheimer's disease patients. Clin Neurophysiol 2001; 112 1860-1867.

46. Iseri PK, Altinas O, Tokay T, Yuksel N. Relationship between cognitive impairment and retinal morphological and visual functional abnormalities in Alzheimer disease. J Neuroophthalmol 2006; 26: 18-24.

47. Ellis KA, Bush Al, Darby D, De Fazio D, Foster J, Hudson P et al. The Australian Imaging, Biomarkers and Lifestyle (AIBL) study of aging: methodology and baseline characteristics of 1112 individuals recruited for a longitudinal study of Alzheimer's disease. Int Psychogeriatr 2009; 21: 672-687.

48. Bourgeat P, Chetelat G, Villemagne VL, Fripp J, Raniga P, Pike K et al. Beta-amyloid burden in the temporal neocortex is related to hippocampal atrophy in elderly subjects without dementia. Neurology 2010; 74: 121-127.

49. Klunk WE, Engler $\mathrm{H}$, Nordberg A, Wang $\mathrm{Y}$, Blomqvist G, Holt DP et al. Imaging brain amyloid in Alzheimer's disease with Pittsburgh Compound-B. Ann Neurol 2004; 55 : 306-319.

50. Klunk WE, Lopresti BJ, Ikonomovic MD, Lefterov IM, Koldamova RP, Abrahamson EE et al. Binding of the positron emission tomography tracer Pittsburgh compound-B reflects the amount of amyloid-beta in Alzheimer's disease brain but not in transgenic mouse brain. $J$ Neurosci 2005; 25: 10598-10606.

51. Villemagne V, Pike K, Fodero-Tavoletti M, Jones G, McLean C, Hinton F et al. Age dependent prevalence of beta-amyloid positive 11C-PiB PET in healthy elderly subjects parallels neuropathology findings. J NUCL MED 2008; 49(MeetingAbstracts_1):34.

52. Cheung CY-L HsuW, Lee ML, Wang JJ, Mitchell P, Lau QP et al. A new method to measure peripheral retinal vascular caliber over an extended area. Microcirculation 2010; 17 : 495-503

53. Hubbard LD, Brothers RJ, King WN, Clegg LX, Klein R, Cooper LS et al. Methods for evaluation of retinal microvascular abnormalities associated with hypertension sclerosis in the Atherosclerosis Risk in Communities Study. Ophthalmology 1999; 106: 2269-2280.

54. Knudtson MD, Lee KE, Hubbard LD, Wong TY, Klein R, Klein BE. Revised formulas for summarizing retinal vessel diameters. Curr Eye Res 2003; 27: 143-149.

55. Mainster MA. The fractal properties of retinal vessels: embryological and clinical implications. Eye 1990; 4(Pt 1): 235-241.

56. Hart WE, Goldbaum M, Cote B, Kube P, Nelson MR. Measurement and classification of retinal vascular tortuosity. Int J Med Inform 1999; 53: 239-252.

57. Chapman N, Dell'omo G, Sartini MS, Witt N, Hughes A, Thom S et al. Peripheral vascular disease is associated with abnormal arteriolar diameter relationships at bifurcations in the human retina. Clin Sci (Lond) 2002; 103: 111-116.

58. King LA, Stanton AV, Sever PS, Thom SA, Hughes AD. Arteriolar length-diameter (L:D) ratio: A geometric parameter of the retinal vasculature diagnostic of hypertension. J Hum Hypertens 1996; 10: 417-418.

59. Benjamini Y, Hochberg Y. Controlling the False Discovery Rate-a Practical and Powerful Approach to Multiple Testing. J Roy Stat Soc B Met 1995; 57: 289-300.

60. Sun C, Wang JJ, Mackey DA, Wong TY. Retinal vascular caliber: systemic, environmental, and genetic associations. Surv Ophthalmol 2009; 54: 74.

61. Alzheimer A. About a peculiar disease of the cerebral cortex. By Alois Alzheimer, 1907 (Translated by L. Jarvik and H. Greenson). Alzheimer Dis Assoc Disord 1987; 1: 3-8.

62. Ellis RJ, Olichney JM, Thal LJ, Mirra SS, Morris JC, Beekly D et al. Cerebral amyloid angiopathy in the brains of patients with Alzheimer's disease: the CERAD experience, Part XV. Neurology 1996; 46: 1592-1596.

63. Jellinger KA. Alzheimer disease and cerebrovascular pathology: an update. $J$ Neura Transm 2002; 109: 813-836.

64. Vinters HV, Wang ZZ, Secor DL. Brain parenchymal and microvascular amyloid in Alzheimer's disease. Brain Pathol 1996; 6: 179-195. 
65. Patton N, Aslam T, Macgillivray T, Pattie A, Deary IJ, Dhillon B. Retinal vascular image analysis as a potential screening tool for cerebrovascular disease: a rationale based on homology between cerebral and retinal microvasculatures. J Anat 2005; 206 : 319-348.

66. Koronyo-Hamaoui M, Koronyo Y, Ljubimov AV, Miller CA, Ko MK, Black KL et al. Identification of amyloid plaques in retinas from Alzheimer's patients and noninvasive in vivo optical imaging of retinal plaques in a mouse model. Neuroimage 2010; 54(Suppl 1): S204-S217.

67. de Jong FJ, Schrijvers EM, Ikram MK, Koudstaal PJ, de Jong PT, Hofman A et al. Retinal vascular caliber and risk of dementia: the Rotterdam study. Neurology 2011; 76: 816-821.

68. Ikram MK, Witteman JCM, Vingerling JR, Breteler MMB, Hofman A, de Jong PTVM. Retinal vessel diameters and risk of hypertension-the Rotterdam Study. Hypertension 2006; 47: 189-194.

69. Kawasaki R, Cheung N, Wang JJ, Klein R, Klein BEK, Cotch MF et al. Retinal vessel diameters and risk of hypertension: the Multiethnic Study of Atherosclerosis. J Hypertens 2009; 27: 2386-2393.
70. Avakian A, Kalina RE, Sage EH, Rambhia AH, Elliott KE, Chuang EL et al. Fractal analysis of region-based vascular change in the normal and non-proliferative diabetic retina. Curr Eye Res 2002; 24: 274-280.

71. Daxer A. Fractal analysis of new vessels in diabetic-retinopathy. Invest Ophthalmol Vis Sci 1993; 34: 718-718.

72. Wong TY, Wang JJ, Rochtchina E, Klein R, Mitchell P. Does refractive error influence the association of blood pressure and retinal vessel diameters? The Blue Mountains Eye Study. Am J Ophthalmol 2004; 137: 1050-1055.

(c) Translational Psychiatry is an open-access journal SOMERTHHISRESERVED published by Nature Publishing Group. This work is licensed under the Creative Commons Attribution-NonCommercial-No Derivative Works 3.0 Unported License. To view a copy of this license, visit http://creativecommons.org/licenses/by-nc-nd/3.0/ 